\title{
GMR
}

\section{miR-218 tissue expression level is associated with aggressive progression of gastric cancer}

\author{
X.X. Wang ${ }^{1}$, S.J. Ge ${ }^{2}$, X.L. Wang ${ }^{2}$ L.X. Jiang ${ }^{1}$, M.F. Sheng ${ }^{2}$ and J.J. Ma ${ }^{2}$ \\ ${ }^{1}$ Department of General Surgery, Yuhuangding Hospital, Yantai, \\ Shandong, China \\ ${ }^{2}$ Department of Oncology, People's Liberation Army 107th Hospital, \\ Yantai, Shandong, China \\ Corresponding author: J.J. Ma \\ E-mail: dr_majianjun@sina.com
}

Genet. Mol. Res. 15 (2): gmr.15027521

Received August 25, 2015

Accepted December 29, 2015

Published June 3, 2016

DOI http://dx.doi.org/10.4238/gmr.15027521

\begin{abstract}
The aim of the present study was to investigate the clinical significance of microRNA-218 (miR-218) in gastric cancer. We enrolled 112 patients having undergone surgery for gastric cancer between May 2008 and June 2014. Expression of miR-218 was determined by real-time quantitative reverse transcription-polymerase chain reaction. Survival curves were plotted using the Kaplan-Meier method and compared by the log-rank test. We found that miR-218 expression was significantly downregulated in gastric cancer tissues compared to adjacent normal tissues $(\mathrm{P}<0.001)$. Low miR-218 expression was significantly associated with tumor differentiation $(\mathrm{P}<0.001)$, depth of tumor invasion $(\mathrm{P}=0.006)$, and tumor node metastasis stage $(\mathrm{P}<0.001)$. Kaplan-Meier survival analysis revealed that patients with low miR-218 levels showed significantly lower 5 -year overall survival than those demonstrating high expression $(\mathrm{P}=$ 0.04). Multivariate Cox regression analyses indicated that low miR218 expression constitutes an independent molecular biomarker for prediction of poor overall survival of gastric cancer patients (hazard ratio $=3.187,95 \%$ confidence interval $=1.551-8.365, \mathrm{P}=0.037)$. In
\end{abstract}


conclusion, miR-218 was remarkably downregulated in gastric cancer tissues and may serve as a prognostic biomarker for patients suffering from this disease.

Key words: miR-218; Expression; Progression; Gastric cancer

\section{INTRODUCTION}

Gastric cancer is the fourth most common malignancy and the second most frequent cause of cancer death worldwide (Siegel et al., 2015). Although its incidence is decreasing, prognosis remains poor, as distant metastasis is present in the majority of cases at the time of diagnosis. A need exists for new biomarkers to more precisely identify patients at high risk of recurrence, and consequently improve personalized cancer care.

MicroRNAs (miRNAs) are endogenous small non-coding RNAs of approximately 1822 nucleotides that have been identified as posttranscriptional regulators of gene expression (Herranz and Cohen, 2010; Krol et al., 2010). miRNAs have important roles in various biological and pathological processes, such as development, cell proliferation, differentiation, apoptosis, inflammation, stress response, and migration. Increasing evidence suggests that miRNAs are deregulated in many types of cancers, acting either as tumor suppressors or oncogenes (Brunetti et al., 2015; Kedmi et al., 2015).

miRNA-218 (miR-218) is expressed in many cancers and plays critical roles in carcinogenesis, including in proliferation and apoptosis (Hu et al., 2015; Liu et al., 2015; Ran et al., 2015; Xie et al., 2015; Zhang et al., 2015b). Its function in gastric cancer has also been investigated. For example, Tie et al. (2010) found that miR-218 inhibits invasion and metastasis in this disease by targeting the ROBO1 receptor. The aim of the present study was to investigate the clinical significance of miR-218 in gastric cancer.

\section{MATERIAL AND METHODS}

\section{Patients and tissue samples}

The present study included 112 gastric cancer patients who had undergone surgery at the Department of General Surgery, Yuhuangding Hospital, between May 2008 and June 2014. All specimens were handled and anonymized according to the relevant ethical and legal standards. No patient had received chemotherapy or radiotherapy prior to surgery. Follow-up data were obtained from medical records and direct communication with the patients or their relatives. The follow-up period was defined as the time between the date of surgery and either the date of patient mortality or the final follow-up in June 2014. This study was approved by the Ethics Committees of Yuhuangding Hospital. Informed consent was obtained from all participants, and the study was performed in accordance with the Declaration of Helsinki. Patient details and tumor characteristics are shown in Table 1.

\section{Real-time quantitative reverse transcription-polymerase chain reaction (qRT-PCR)}

Total RNA was isolated from tissue samples using a mirVana miRNA Isolation kit (Ambion Life Technologies, Carlsbad, CA, USA). qRT-PCR was performed on an Applied 
miR-218 expression in gastric cancer tissues

Biosystems 7500 Real-Time PCR system (Applied Biosystems, Waltham, MA, USA), using the following cycling conditions: denaturation at $95^{\circ} \mathrm{C}$ for $30 \mathrm{~s}$, then 30 cycles of annealing at $60^{\circ} \mathrm{C}$ for $30 \mathrm{~s}$ and extension at $72^{\circ} \mathrm{C}$ for $30 \mathrm{~s}$, before samples were held at $4{ }^{\circ} \mathrm{C}$ until further analysis. Sequences of the primers used to amplify miR-218 were as follows: forward, 5'AAG ACA CCC TGG ACG AAG CC-3'; and reverse, 5'-ACA ACC AGA GTC CAC CGG CG-3'. miR-218 expression was normalized to RNU6B levels using the $2^{-\Delta \Delta C t}$ method.

\section{Statistical analysis}

SPSS version 18.0 (SPSS Inc., Chicago, IL, USA) was used for statistical analysis. Comparisons between quantitative data were made using the $t$-test. The association between miR-218 expression and clinicopathologic factors among gastric cancer patients was analyzed using the chi-square test. Survival curves were plotted using the Kaplan-Meier method and compared using the log-rank test. P values $<0.05$ were considered significant.

\section{RESULTS}

\section{miR-218 is downregulated in gastric cancer tissues}

We used qRT-PCR to examine the expression of miR-218 in gastric cancer tissues and adjacent normal tissues. Based on this comparison, we found that miR-218 was significantly downregulated in the former (Figure 1; $\mathrm{P}<0.001$ ). To investigate the association between miR-218 levels and clinicopathologic variables in gastric cancer, 112 patients suffering from this disease were divided into two groups according to the median miR-218 expression value: the low miR-218 group (patients expressing this miRNA at levels below the cut-off value; $\mathrm{N}=$ 57), and the high miR-218 group (those expressing miR-218 at levels greater than the cut-off value; $\mathrm{N}=55$ ).

\section{miR-218 downregulation is associated with aggressive progression of gastric cancer}

Associations between miR-218 expression and clinicopathologic features of gastric cancer are summarized in Table 1. Our results revealed that low miR-218 levels were significantly associated with tumor differentiation $(\mathrm{P}<0.001)$, lymph node metastasis $(\mathrm{P}=$ $0.145)$, depth of tumor invasion $(\mathrm{P}=0.006)$, and tumor node metastasis (TNM) stage $(\mathrm{P}<$ 0.001 ), indicating that downregulation of this miRNA is associated with aggressive progression of gastric cancer.

\section{miR-218 downregulation predicts poor prognosis in patients with gastric cancer}

Kaplan-Meier survival analysis was performed to analyze the association between miR218 expression and overall survival in gastric cancer patients. We found that patients exhibiting low expression had a significantly lower 5-year overall survival than those expressing high levels of miR-218 (Figure 2; $\mathrm{P}=0.04$ ). Moreover, multivariate Cox regression analyses identified low miR-218 expression as an independent molecular biomarker predicting poor overall survival of gastric cancer patients (Table 2; hazard ratio $=3.187,95 \%$ confidence interval: $1.551-8.365, \mathrm{P}$ $=0.037$ ), indicating that such expression might be used as a marker in prognosis. 


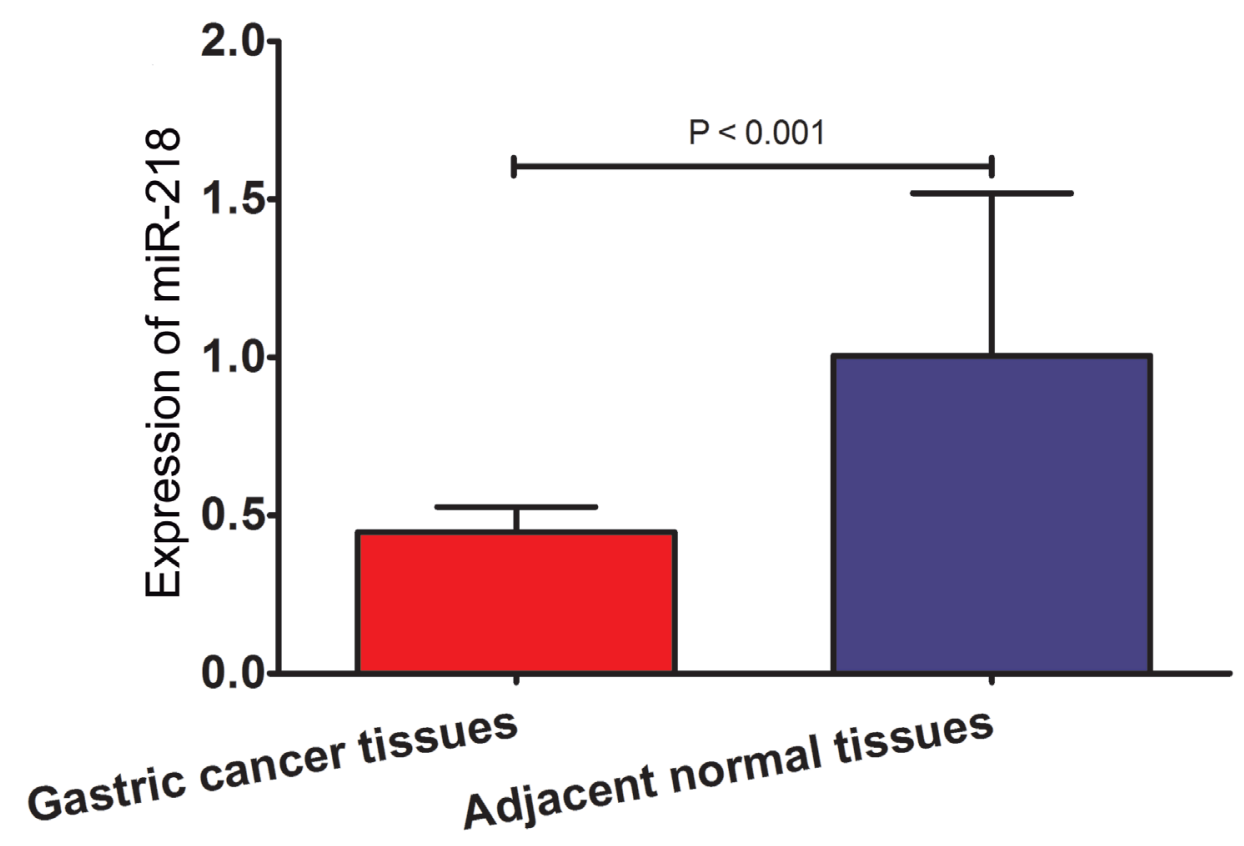

Figure 1. Relative miR-218 expression in gastric cancer tissues and adjacent normal tissues.

\begin{tabular}{|c|c|c|c|c|}
\hline \multirow[t]{2}{*}{ Clinicopathologic variables } & \multirow[b]{2}{*}{ Number } & \multicolumn{2}{|c|}{ miR-218 expression level } & \multirow[t]{2}{*}{$\mathrm{P}$ value } \\
\hline & & Low $(\mathrm{N}=57)$ & High $(\mathrm{N}=55)$ & \\
\hline \multicolumn{5}{|l|}{ Age (years) } \\
\hline$\leq 60$ & 53 & 23 & 30 & 0.185 \\
\hline$>60$ & 59 & 34 & 25 & \\
\hline \multicolumn{5}{|l|}{ Gender } \\
\hline Male & 65 & 34 & 31 & 0.848 \\
\hline Female & 47 & 23 & 24 & \\
\hline \multicolumn{5}{|l|}{ Tumour differentiation } \\
\hline Moderate/well & 67 & 20 & 47 & $<0.001$ \\
\hline Poorly & 45 & 37 & 8 & \\
\hline \multicolumn{5}{|l|}{ Tumor size $(\mathrm{cm})$} \\
\hline$\leq 5$ & 71 & 32 & 39 & 0.120 \\
\hline$>5$ & 41 & 25 & 16 & \\
\hline \multicolumn{5}{|l|}{ Venous invasion } \\
\hline Presence & 29 & 16 & 13 & 0.669 \\
\hline Absence & 83 & 41 & 42 & \\
\hline \multicolumn{5}{|l|}{ Lymph node metastasis } \\
\hline Presence & 32 & 20 & 12 & 0.145 \\
\hline Absence & 80 & 37 & 43 & \\
\hline \multicolumn{5}{|l|}{ Depth of tumor invasion } \\
\hline Mucosa, submucosa, muscularis propria, subserosa & 73 & 30 & 43 & 0.006 \\
\hline Penetration of serosa, adjacent structures & 39 & 27 & 12 & \\
\hline \multicolumn{5}{|l|}{ TNM stage } \\
\hline I-II & 69 & 26 & 43 & $<0.001$ \\
\hline III-IV & 43 & 31 & 12 & \\
\hline
\end{tabular}




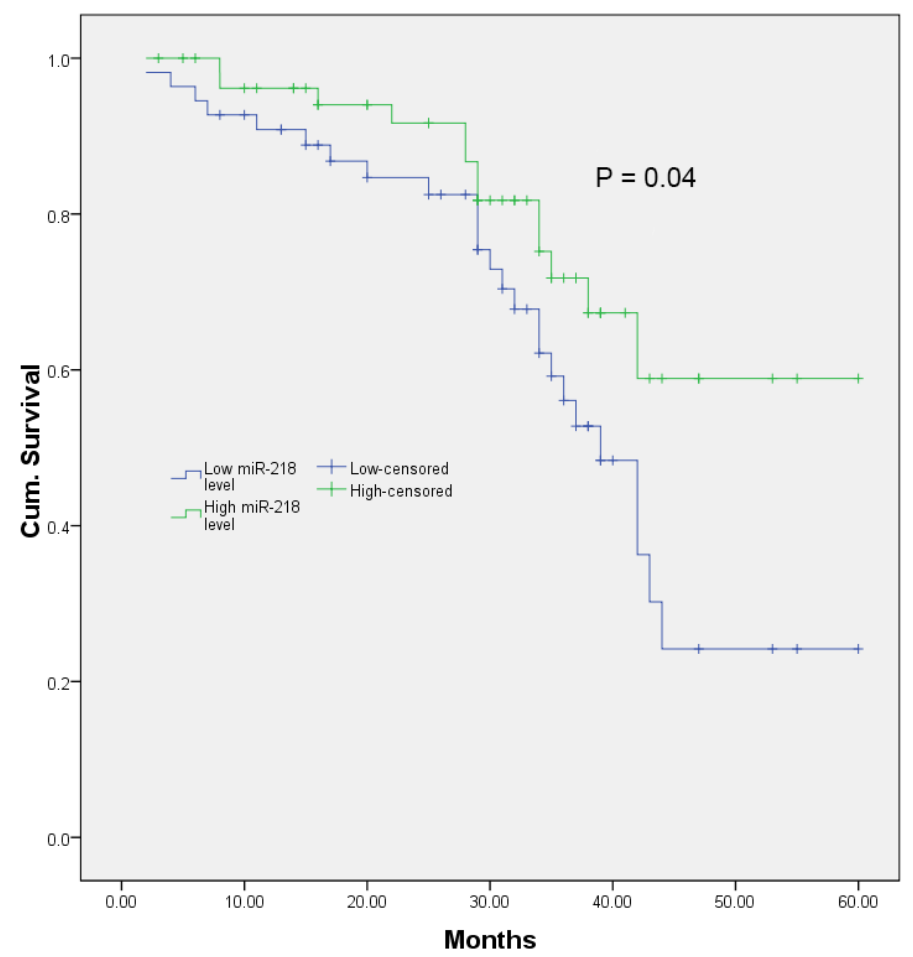

Figure 2. Low miR-218 expression is significantly associated with poor overall survival of gastric cancer patients.

Table 2. Multivariate Cox regression analysis of potential prognostic factors for survival in patients with gastric
cancer.
\begin{tabular}{l|c|c|c}
\hline Variables & HR & $95 \% \mathrm{CI}$ & P value \\
\hline Age & 1.102 & $0.672-1.829$ & 0.283 \\
\hline Gender & 0.791 & $0.273-2.993$ & 0.569 \\
\hline Tumor differentiation & 2.393 & $1.038-7.921$ & 0.035 \\
\hline Tumor size & 1.993 & $0.791-3.256$ & 0.078 \\
\hline Venous invasion & 2.192 & $0.911-4.198$ & 0.061 \\
\hline Lymph node metastasis & 3.773 & $2.012-10.923$ & 0.014 \\
\hline Depth of tumor invasion & 2.192 & $0.917-6.119$ & 0.058 \\
\hline TNM stage & 3.529 & $2.593-10.935$ & 0.008 \\
\hline miR-218 expression level & 3.187 & $1.551-8.365$ & 0.037 \\
\hline
\end{tabular}

$\mathrm{HR}=$ hazard ratio; $\mathrm{CI}=$ confidence interval.

\section{DISCUSSION}

Despite recent advances in diagnostic methods, surgical technique, and new chemotherapy regimens, the long-term survival rate for gastric cancer remains relatively low (Katada et al., 2009; Thiel and Ristimäki, 2012). In many patients, this cancer is diagnosed at an advanced stage, with extensive invasion and lymphatic metastasis already having occurred. The success of therapeutic strategies is limited and mortality is high (Yasui et al., 2011). 
Therefore, there is an urgent need to investigate the fundamental molecular mechanisms underlying drug resistance, histological heterogeneity, and development of metastasis in gastric cancer, and to identify novel markers for its diagnosis and treatment.

miRNAs play critical roles in many biological processes, including cell proliferation, development, differentiation, and apoptosis. Furthermore, miRNAs have been shown to act as oncogenes or tumor suppressors during tumorigenesis (Kishikawa et al., 2015; Neviani and Fabbri, 2015). Recent studies have demonstrated that many miRNAs affect proliferation and invasion in gastric cancer. For example, Chen et al. (2015) found that miR-145 regulates cell migration and invasion in this disease, primarily by directly targeting FSCN1. Shen et al. (2014) found that miR-410 acts as a tumor suppressor by targeting the MDM2 gene and inhibiting gastric cancer cell proliferation, migration, and invasion. In addition, also in relation to gastric cancer, Peng et al. (2014) identified miR-338 as a novel tumor suppressor, describing its ability to decrease migratory, invasive, proliferative, and apoptotic behaviors, as well as epithelial-mesenchymal transition by attenuating the expression of NRP1.

miR-218 is expressed in many cancers and plays critical roles in carcinogenesis, including in proliferation and apoptosis (Hu et al., 2015; Liu et al., 2015; Ran et al., 2015; Xie et al., 2015; Zhang et al., 2015b). For instance, Tie et al. (2010) found that miR-218 inhibits invasion and metastasis in gastric cancer by targeting the ROBO1 receptor. Zhang et al. (2014) reported that this miRNA is upregulated following cytoreductive surgery and hyperthermic intraperitoneal chemotherapy for gastric cancer, and increases chemosensitivity to cisplatin, indicating that targeting miR-218 might provide a strategy to block the development of this illness and reverse multidrug resistance of gastric cancer cells. Their subsequent research efforts found that miR-218 levels are lower in multidrug-resistant gastric cancer cells than in chemosensitive parental cells. Treatment with miR-218 mimic increases the sensitivity of gastric cancer cells to chemotherapeutic drugs by simultaneously inhibiting drug efflux and accelerating apoptosis. These findings suggest that miR-218 might modulate multidrug resistance in gastric cancer cells (Zhang et al., 2015a).

The aim of the present study was to investigate the clinical significance and prognostic value of miR-218 in gastric cancer, using qRT-PCR to examine its expression in malignant tissues and adjacent normal tissues. We found miR-218 levels to be significantly downregulated in the former compared to the latter. We then investigated associations between miR-218 expression and clinicopathologic features of gastric cancer patients. Our results revealed that low levels were significantly associated with tumor differentiation, lymph node metastasis, depth of tumor invasion, and TNM stage, indicating that miR-218 downregulation is associated with aggressive progression in this disease. Kaplan-Meier survival analysis was performed to analyze the association between miR-218 expression and overall survival of gastric cancer patients. We observed that patients expressing low levels of this miRNA demonstrated a significantly reduced 5-year overall survival compared to those with high miR-218 expression. Multivariate Cox regression analyses indicated that low expression represents an independent molecular biomarker for the prediction of decreased overall survival of gastric cancer patients, suggesting its use as a biomarker of poor prognosis. In conclusion, miR-218 was found to be remarkably downregulated in gastric cancer tissues and may serve as a potential prognostic biomarker for gastric cancer patients.

\section{Conflicts of interest}

The authors declare no conflict of interest. 
miR-218 expression in gastric cancer tissues

\section{REFERENCES}

Brunetti O, Russo A, Scarpa A, Santini D, et al. (2015). MicroRNA in pancreatic adenocarcinoma: predictive/prognostic biomarkers or therapeutic targets? Oncotarget 6: 23323-23341. http://dx.doi.org/10.18632/oncotarget.4492

Chen JJ, Cai WY, Liu XW, Luo QC, et al. (2015). Reverse Correlation between MicroRNA-145 and FSCN1 Affecting Gastric Cancer Migration and Invasion. PLoS One 10: e0126890. http://dx.doi.org/10.1371/journal.pone.0126890

Herranz H and Cohen SM (2010). MicroRNAs and gene regulatory networks: managing the impact of noise in biological systems. Genes Dev. 24: 1339-1344. http://dx.doi.org/10.1101/gad.1937010

$\mathrm{Hu}$ Y, Xu K and Yagüe E (2015). miR-218 targets survivin and regulates resistance to chemotherapeutics in breast cancer. Breast Cancer Res. Treat. 151: 269-280. http://dx.doi.org/10.1007/s10549-015-3372-9

Katada T, Ishiguro H, Kuwabara Y, Kimura M, et al. (2009). microRNA expression profile in undifferentiated gastric cancer. Int. J. Oncol. 34: 537-542.

Kedmi M, Sas-Chen A and Yarden Y (2015). MicroRNAs and Growth Factors: An Alliance Propelling Tumor Progression. J. Clin. Med. 4: 1578-1599. http://dx.doi.org/10.3390/jcm4081578

Kishikawa T, Otsuka M, Ohno M, Yoshikawa T, et al. (2015). Circulating RNAs as new biomarkers for detecting pancreatic cancer. World J. Gastroenterol. 21: 8527-8540. http://dx.doi.org/10.3748/wjg.v21.i28.8527

Krol J, Loedige I and Filipowicz W (2010). The widespread regulation of microRNA biogenesis, function and decay. Nat. Rev. Genet. 11: 597-610.

Liu Z, Du R, Long J, Guo K, et al. (2015). microRNA-218 promotes gemcitabine sensitivity in human pancreatic cancer cells by regulating HMGB1 expression. Chin. J. Cancer Res. 27: 267-278.

Neviani P and Fabbri M (2015). Exosomic microRNAs in the Tumor Microenvironment. Front Med (Lausanne) 2: 47. http://dx.doi.org/10.3389/fmed.2015.00047

Peng Y, Liu YM, Li LC, Wang LL, et al. (2014). MicroRNA-338 inhibits growth, invasion and metastasis of gastric cancer by targeting NRP1 expression. PLoS One 9: e94422. http://dx.doi.org/10.1371/journal.pone.0094422

Ran X, Yang J, Liu C, Zhou P, et al. (2015). MiR-218 inhibits HMGB1-mediated autophagy in endometrial carcinoma cells during chemotherapy. Int. J. Clin. Exp. Pathol. 8: 6617-6626.

Shen J, Niu W, Zhou M, Zhang H, et al. (2014). MicroRNA-410 suppresses migration and invasion by targeting MDM2 in gastric cancer. PLoS One 9: e104510. http://dx.doi.org/10.1371/journal.pone.0104510

Siegel RL, Miller KD and Jemal A (2015). Cancer statistics, 2015. CA Cancer J. Clin. 65: 5-29. http://dx.doi.org/10.3322/ caac. 21254

Thiel A and Ristimäki A (2012). Gastric cancer: basic aspects. Helicobacter 17 (Suppl 1): 26-29. http://dx.doi.org/10.1111/ j.1523-5378.2012.00979.x

Tie J, Pan Y, Zhao L, Wu K, et al. (2010). MiR-218 inhibits invasion and metastasis of gastric cancer by targeting the Robo1 receptor. PLoS Genet. 6: e1000879. http://dx.doi.org/10.1371/journal.pgen.1000879

Xie J, Yu F, Li D, Zhu X, et al. (2015). MicroRNA-218 regulates cisplatin (DPP) chemosensitivity in non-small cell lung cancer by targeting RUNX2. Tumour Biol. 10.1007/s13277-015-3831-2.

Yasui W, Sentani K, Sakamoto N, Anami K, et al. (2011). Molecular pathology of gastric cancer: research and practice. Pathol. Res. Pract. 207: 608-612. http://dx.doi.org/10.1016/j.prp.2011.09.006

Zhang XL, Shi HJ, Wang JP, Tang HS, et al. (2014). MicroRNA-218 is upregulated in gastric cancer after cytoreductive surgery and hyperthermic intraperitoneal chemotherapy and increases chemosensitivity to cisplatin. World $J$. Gastroenterol. 20: 11347-11355. http://dx.doi.org/10.3748/wjg.v20.i32.11347

Zhang XL, Shi HJ, Wang JP, Tang HS, et al. (2015a). MiR-218 inhibits multidrug resistance (MDR) of gastric cancer cells by targeting Hedgehog/smoothened. Int. J. Clin. Exp. Pathol. 8: 6397-6406.

Zhang Y, Han D, Wei W, Cao W, et al. (2015b). MiR-218 Inhibited Growth and Metabolism of Human Glioblastoma Cells by Directly Targeting E2F2. Cell. Mol. Neurobiol. 35: 1165-1173. http://dx.doi.org/10.1007/s10571-015-0210-x 